\section{Vermaak en vertier onder toezicht}

\author{
CASUS Jelle Brands
}

\section{Lokale overheden zetten in op leuk én veilig uitgaan in de binnenstad. Maar veiligheid is een gevoel, dus hoe meet of bevorder je dat? Een slimme combinatie van politie- en cameratoezicht met aandacht voor de 'zachte' omgevingsfactoren lijkt de sleutel tot succes.}

Steden zijn gebaat bij een veilige uitgaansbeleving. Bij gevoelens van onveiligheid zullen bezoekers minder vaak komen wat ten koste gaat van de concurrentiepositie ten opzichte van andere steden. Met toezichthouding in uitgaansgebieden, zoals extra inzet van politieagenten en de plaatsing van camera's, wordt beoogd de veiligheid te bevorderen. Hoe effectief het gevoerde beleid is, wordt vaak onderzocht op basis van het veiligheidsgevoel. Het toekennen van een getal of percentage aan het gevoel van veiligheid zegt echter weinig over de complexe mix van gevoelens en emoties tijdens een avond uit. Wat betekent 'je veilig voelen' nu eigenlijk? Zolang we niet precies weten wat een ervaring van (on)veiligheid inhoudt, zijn pogingen om er wat aan te doen vooral symbolisch en mogelijk zelfs contraproductief. De vraag hoe, in plaats van of, uitgaanspubliek (on)veiligheid ervaart, staat daarom centraal in dit artikel.

Om de (on)veiligheidsbeleving tijdens een avond uit te onderzoeken zijn interviews afgenomen met bezoekers van uitgaansgebieden in Utrecht (8 respondenten), Rotterdam (5 respondenten) en Groningen (5 respondenten). Het gaat om evenveel mannen als vrouwen, tussen de 16 en 34 jaar. Deze selectie is tot stand gekomen door telkens 'eerste voorbijgangers' in de genoemde uitgaansgebieden aan te spreken met de vraag om deel te nemen aan een interview. Geïnteresseerden zijn enige tijd later geïnterviewd. In dit artikel worden pseudoniemen gebruikt om de privacy van de geïnterviewden te waarborgen.

Het onderzoek onderscheidt drie gedeelde fasen van (on)veiligheidsbeleving onder deze bezoekers: onbewuste veiligheid, 'op je hoede' en directe dreiging. Wat houden deze drie fasen precies in en wat zijn de effecten van politietoezicht en cameratoezicht hierop?

\section{Onbewuste veiligheid}

In lijn met de uitkomsten van ander onderzoek naar de ervaring van veiligheid, voelen ook onze respondenten zich tijdens het uitgaan doorgaans veilig. Wel vinden ze het lastig om veiligheid te verwoorden. Waarom een 'gevoel' moeilijk te verwoorden is kan toegelicht worden aan de hand van fenomenologisch onderzoek. Zoals Heidegger beargumenteert, is de wereld in veel gevallen 'zuhanden': zaken zijn bekend en vertrouwd. In een dergelijke situatie blijken personen zich veelal onbewust van hun waarneming, en hun rol als waarnemer. Met andere woorden: ervaring is in veel gevallen pre-reflectief van aard, en daarmee moeilijk te duiden. Zo ook veiligheidservaring: "bij veiligheid, voor mij, dan komt het woord warmte in me op. Maar dat is dus warmte van mensen om me heen, de sfeer waarin ik zit, welke plek ik ben". [En] "als je je ergens hartstikke veilig voelt, let je totaal niet op [je omgeving]" aldus Amelie. Leuke mensen om haar heen, maar bijvoorbeeld ook verlichting of de aankleding van de ruimte zorgen ervoor dat Amelie 'warmte' voelt, wat zij met veiligheid associeert. Omdat ze deze warmte voelt, is ze zich niet bewust van haar eigen veiligheid. Een situatie die we ons zouden kunnen voorstellen is er één waarbij Amelie met vriendinnen over een plein vol met mensen loopt, en druk aan het kletsen is over wat ze meegemaakt heeft de afgelopen week, waarbij 'het plein' en 'de mensen om haar heen' zich aan haar bewustzijn onttrekken. De onbewuste ervaring van een situatie die bekend en vertrouwd is, 'zuhanden' is, staat dus centraal in het beleven van veiligheid tijdens het uitgaan en niet die zaken die aanleiding geven om bewust te worden van het eigen veiligheidsgevoel.

\section{'Op je hoede'}

Onbewuste veiligheid, zoals hierboven beschreven, kan tijdens een avond uit worden onderbroken als er iets anders gebeurt dan normaal gesproken. De wereld wordt dan 'vorhanden'. Er treedt een impuls op die belemmerend en vervreemdend werkt, wat het bewustzijn in de hand werkt. Personen raken op hun hoede. llya illustreert dit als volgt: "als je op je hoede bent dan ben je dus wat ik zeg bezig met de omgeving en dan houd je rekening met eventueel onheil. [...] Dat bewustzijn moet wel op de één of andere manier gealarmeerd worden [...] door mijn omgeving, door mensen in die omgeving, of doordat het

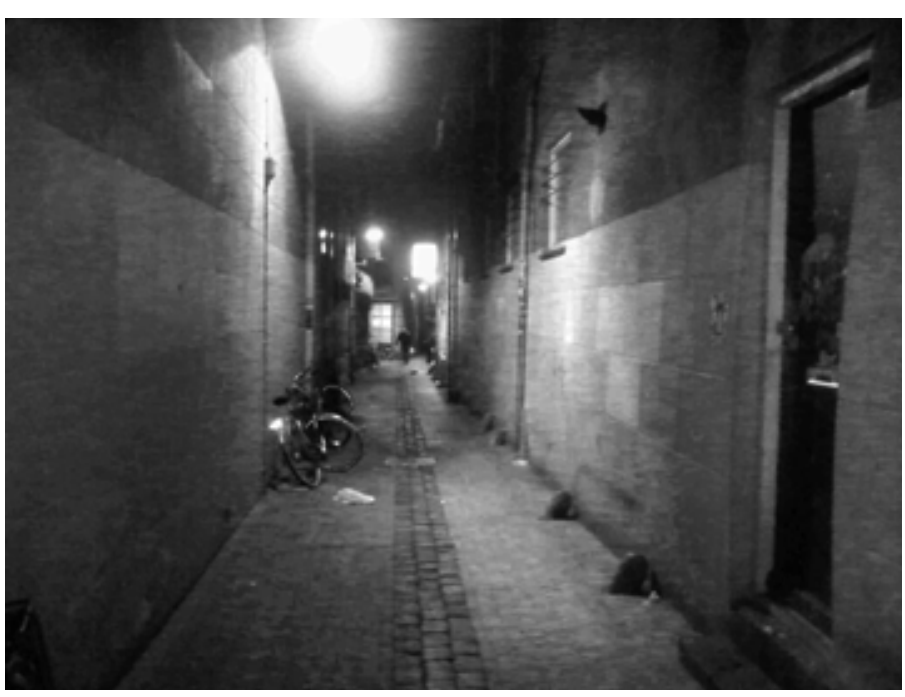

De Papengang in Groningen. Foto: Natalie 


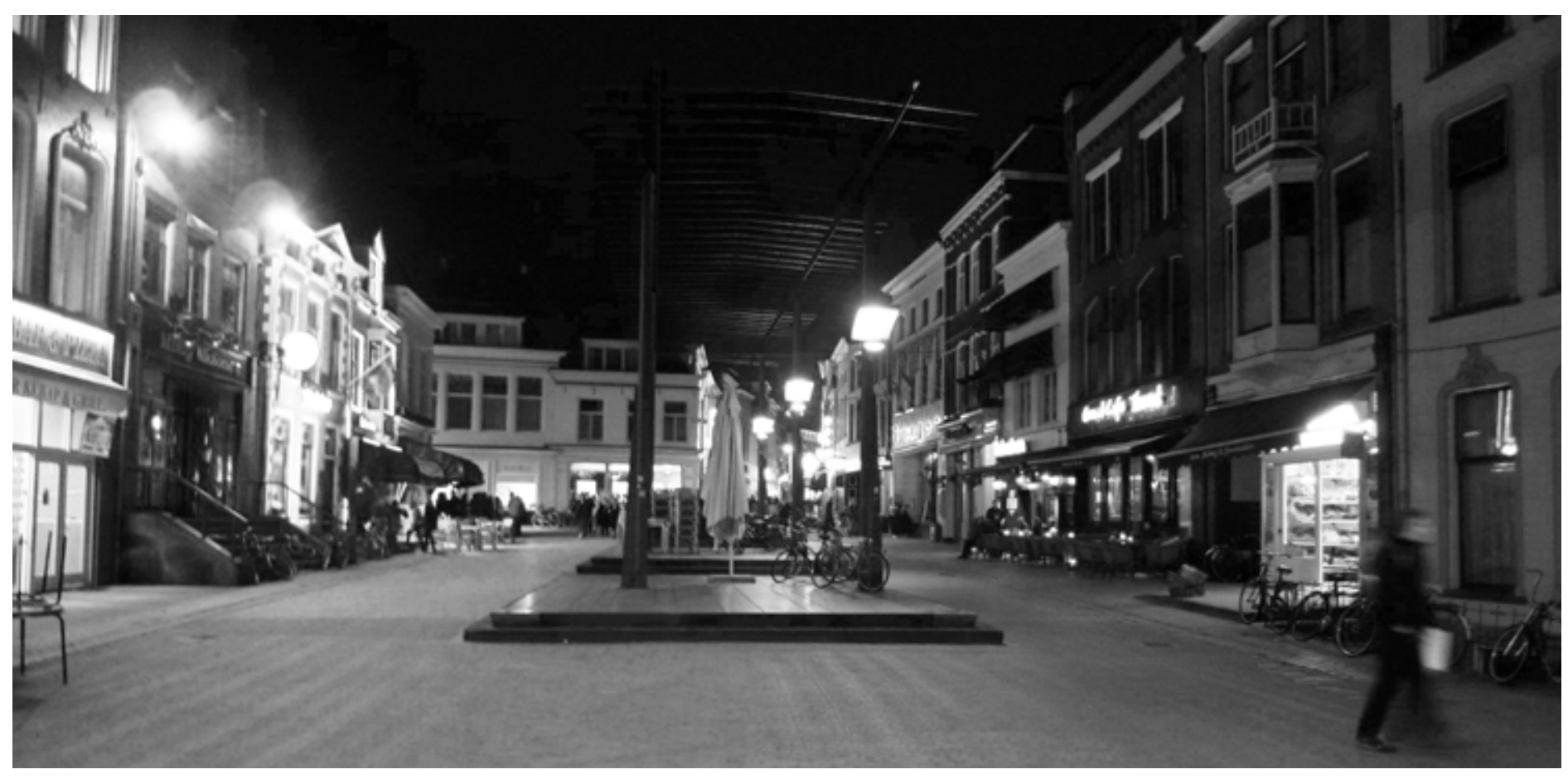

Poelestraat, Groningen. Foto: Jelle Brands

gebied waar ik heen ga een slechte reputatie heeft". Natalie refereert aan een zelfde soort ervaring, in relatie tot een steegje: "In de rest van Groningen kan ik gewoon gedachteloos rondlopen. En een beetje ouwehoeren. Hier [Papengang, Groningen, zie foto], zit je een beetje om je heen te kijken [...] Het valt uit de toon met de rest van Groningen. Dan raak ik meer op mijn hoede. [...] Het is een heel nauw steegje. Weinig licht. Het stinkt er. Het stinkt er echt heel erg! En dat beklemmende van die hoge muren. Zo'n duister steegje. Dat geeft je ook meteen zo'n duistere sfeer aan aandacht van mensen. Zeker als je ziet dat ze uit de Zolder komen gelopen. Dat is die coffeeshop". Ilya en Natalie zijn op hun hoede omdat ze een negatieve gebeurtenis anticiperen op basis van de samenkomst van verschillende elementen: geur, gebouwen, muren, verlichting, anderen en de functie van een pand. Beide citaten illustreren ook dat herinnering er toe doet binnen ervaring. Zowel llya als Natalie hebben vanuit het verleden meegekregen - zij het op basis van eerstehands ervaring dan wel op basis van andermans verhalen - niet door steegjes te lopen en bijvoorbeeld op weg naar huis niet door parken te fietsen omdat 'daar dingen gebeuren die niet pluis zijn'. Komen de geïnterviewden toch in een dergelijke omgeving terecht "dan is het gewoon meer van dat ik heel alert ben, omdat ik denk dat er wat kan gebeuren", aldus Aniek. Er wordt zo snel mogelijk een uitweg gezocht zodat er weer onbekommerd door het uitgaansgebied gemanoeuvreerd kan worden.

\section{Directe dreiging}

Op je hoede zijn staat echter niet één-op-één met een daadwerkelijke ervaring van onveiligheid: in het eerste geval, legt Aniek uit, "is de angst minder direct" omdat het slechts de verwachting betreft dat er wat negatiefs zou kunnen gebeuren. De directe en bewuste waarneming en ervaring van iets of iemand die kwaad zou kunnen doen, is wat directe dreiging oplevert. Echter, zoals Lucy toevoegt, is in het bijzonder de intentie van de ander hierbij van doorslaggevend belang: "Ik denk dat het pas echt onveilig wordt als iemand duidelijk nare ideeën met me heeft. In een situatie waarin ik niet 'weg' kan. Dan ga ik me onveilig voelen". Een dergelijke ervaring wordt goed geillustreerd door Amelie: "Daar [een plek in haar geboorteplaats] heb je wel eens van die muizentunneltjes dat zijn van die hele rare, unheimische [naargeestige] plekjes. [...] En toen heb ik een keer meegemaakt in die tunnel dat een man mij tegemoet kwam en op het moment dat ik hem passeerde heeft hij zich omgedraaid en ging hij heel hard achter me aan fietsen. Dus dat was voor mij beangstigend, van iemand draait zich nou super bewust om, op een plek waar het helemaal verlaten is". Opvallend is dat de geïnterviewden directe dreiging in het nachtleven enkel in termen van menselijk handelen bespreken. Dit gevoel kan echter versterkt worden door de omgeving - zoals het voorbeeld van Amelie illustreert. Het onveiligheidsgevoel dat het bewust omkeren van de man oproept wordt versterkt door de verlaten omgeving. Een 'naargeestige tunnel', graffiti, straatvuil of de gebouwde omgeving veroorzaken geen daadwerkelijke dreiging, maar zorgen ervoor dat bezoekers van uitgaansgebieden op hun hoede raken.

\section{Het gaat om de onbewuste ervaring van een situatie die bekend en vertrouwd is}

\section{Naar onbewuste veiligheid!}

Onderzoekers en journalisten stellen vaak de vraag of toezichtvormen, zoals camera- en politietoezicht, de door het uitgaanspubliek ervaren veiligheidsbeleving kunnen bevorderen. Een belangrijke vraag is hoe dergelijk toezicht zich tot de beschreven fases van veiligheidservaring verhoudt. Op de meeste momenten en plekken tijdens het uitgaan 


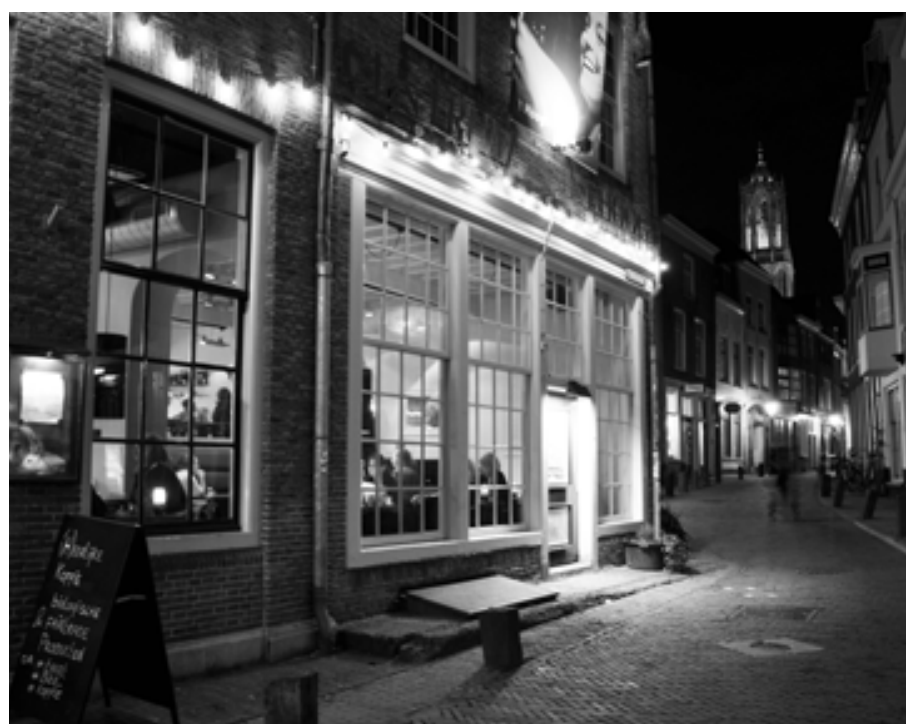

Slachtstraat, Utrecht. Foto: Irina van Aalst

bleken de geïnterviewden onbewust veiligheid te ervaren. Daarbij gaven zij aan zich ook in veel gevallen niet bewust te zijn van de aanwezigheid van politieagenten en camera's. Dit heeft een aantal implicaties. Antwoord op vragen in hoeverre cameratoezicht en politietoezicht bijdragen aan de onbewuste ervaring van veiligheid kunnen niet zomaar gebruikt worden om hun effecten te legitimeren. Immers, het hiernaar vragen gaat voorbij aan deze onbewuste ervaring Juist doordat Natalie en anderen zich 'al veilig voelen' kunnen zij moeilijk tot een gegrond oordeel komen: "ja, het is sowieso dat je zeg maar de vragen allemaal stelt [over toezichthouding], terwijl ik er [over veiligheid] echt nooit over nadenk". Desalniettemin is het aannemelijk dat camera- en politietoezicht wel bijdraagt aan de ervaring van onbewuste veiligheid: "het [cameratoezicht] is een beetje de kers op de slagroomtaart", is Liams mening wanneer we vragen hoe hij denkt dat toezicht onbewuste veiligheid beïnvloedt. Dit geldt in veel gevallen ook voor politietoezicht: de geïnterviewden zijn van mening dat, wanneer veiligheid onbewust wordt ervaren, politietoezicht veelal een 'extra' is. "Als ik gewoon op een plek ben waar ik op mijn gemak ben en als ik dan ook nog zie dat er politieagenten staan dan heb ik niet zo iets van nou, nu voel ik me drie keer zo veilig.", aldus Valerie.

Het daadwerkelijke nut en de noodzaak van camera- en politietoezicht kan dus enkel beoordeeld worden in de gevallen dat personen op hun hoede raken of directe dreiging ervaren. Uit de interviews komt naar voren dat de effecten sterk verschillen tussen camera- en politietoezicht (zie figuur). Opvallend is dat zichtbare aanwezigheid van (grote aantallen) politieagenten tijdens een avond uit contraproductief kan werken en kan leiden tot verschuivingen van onbewuste veiligheid naar op de hoede zijn: "blauw op straat [is] OK, maar liever niet te veel want dan gaan mensen zich daar mee bezig houden van wat doen die hier allemaal". Als er "echt zes politieauto's zijn denk ik van oh, shit, er is iets gebeurd", aldus respectievelijk llya en Leon. In andere situaties waarin mensen al op hun hoede zijn of directe dreiging ervaren, wordt de aanwezigheid van politie wel duidelijk als 'positief' beoordeeld. Dit is anders bij cameratoezicht. Enerzijds blijkt de aanwezigheid van camera's geen teken dat er wat (negatiefs) zou kunnen gebeuren. Anderzijds vertellen de respondenten dat ze bijna nooit aan de camera's denken wanneer zij op hun hoede zijn of wanneer zij directe dreiging ervaren. De bezoekers van de uitgaansgebieden refereren voornamelijk aan camera's als passieve machines die niet helpen om incidenten en misdrijven te voorkomen en hooguit 'achteraf' van pas komen bij de opsporing en berechting van daders. Politieagenten daarentegen, zijn zichtbaarder, menselijker en reactiever en zullen spoediger van hulp voorzien in geval van nood.

\section{Leuk én veilig uitgaan?}

Wat betekent dit nu voor veilig uitgaansbeleid en de inzet van politie en cameratoezicht? Allereerst blijken zowel de inzet van camera's als politieagenten binnen het nachtleven niet altijd even effectief, soms zijn ze zelfs contraproductief. Wat er van toezicht gevraagd wordt, verschilt in situaties waarin er druk kletsend met vriendinnen over een groot plein wordt gewandeld (Amelie) of wanneer er alleen door een geurende, donkere steeg wordt gewandeld (Natalie). Waar het om draait is een inzet van toezicht dat proportioneel is en afgestemd is op het dynamische en veelzijdige decor van een avond uit, in plaats van een 'one-sizefits-all'-benadering. Hierdoor worden wat ons betreft de mogelijkheden vergroot om uitgaan zowel leuk als veilig te houden.

\section{'Zero-tolerance'-beleid slaat de plank mis}

Omdat het overgrote deel van de respondenten een avond uitgaan ervaart met een onbewust veiligheidsgevoel, draait toezichthouding in eerste instantie en vooral om het continueren van dit veiligheidsgevoel. Veel gemeentelijk beleid vertrekt echter vanuit een 'negatiever' standpunt waarbij ervaringen van 'onveiligheid' moeten worden onderdrukt. Echter, wil je op een positieve manier invloed uitoefenen op de veiligheidsbeleving dan lijkt inzetten op een 'soft focus' noodzakelijk. Daarmee wordt een warme, inclusieve, comfortabele, welkome, huiselijke en 'menselijke' sfeer binnen het uitgaansleven behouden. Het is aannemelijk dat onbewuste veiligheid het sterkst gecontinueerd wordt wanneer toezichthouding 'wegzinkt' binnen het decor van het uitgaansgebied. De nadrukkelijke aanwezigheid van politietoezicht, busjes, paarden, honden, en het voeren van een zogenaamd 'zero-

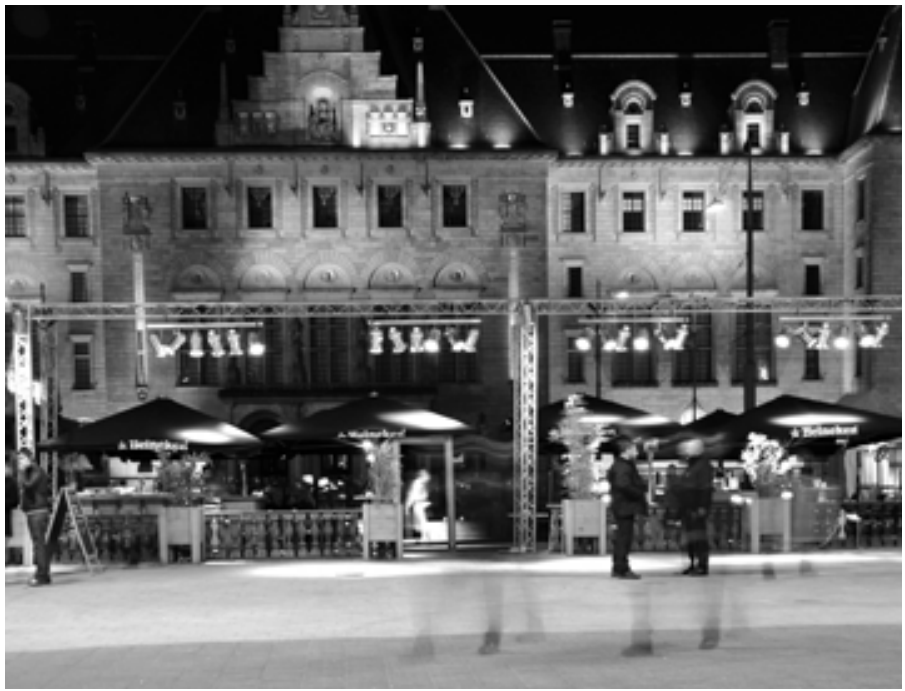

Stadhuisplein, Rotterdam. Foto: Irina van Aalst 


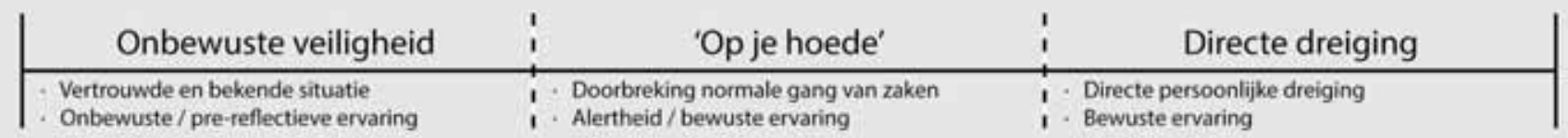
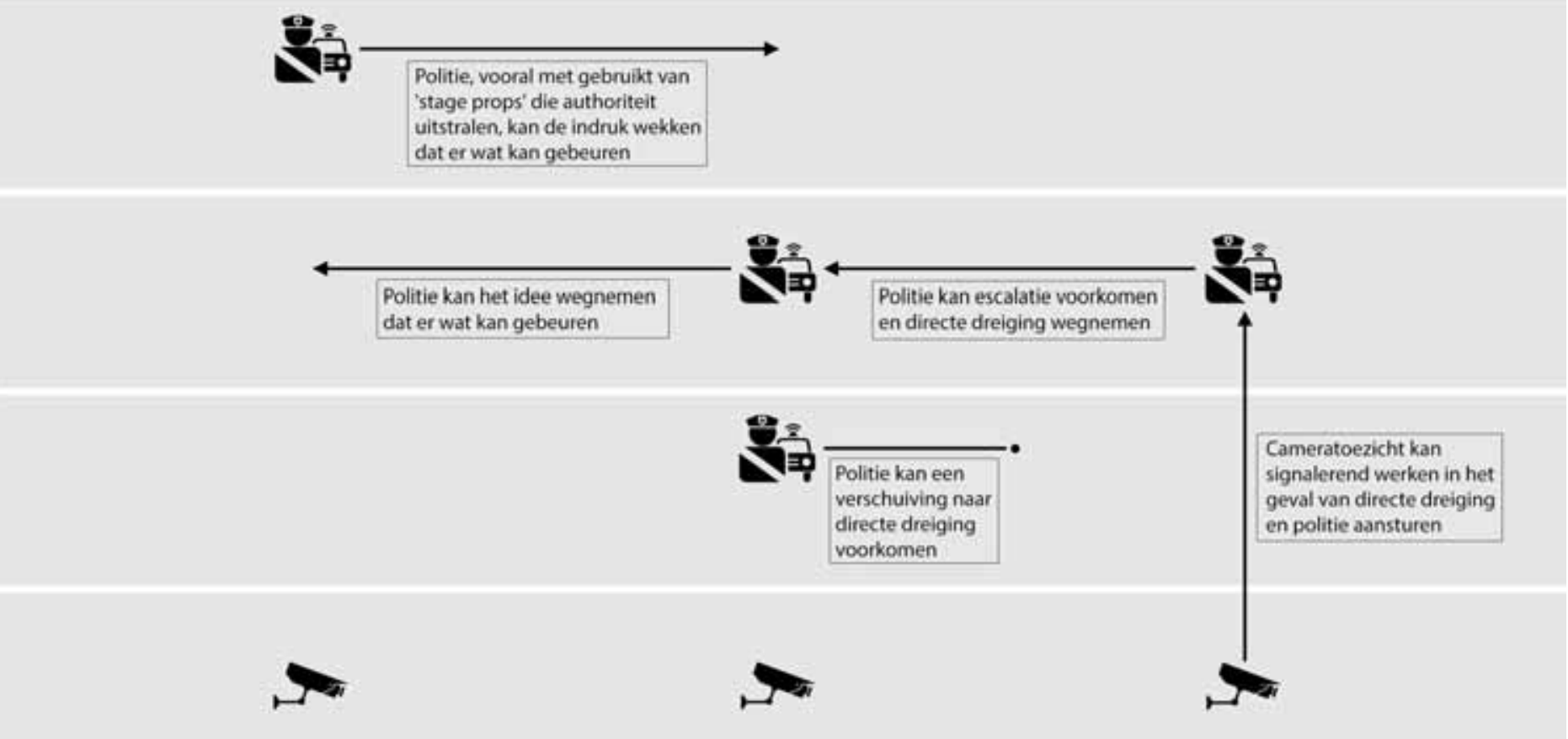

Effecten van camera- en politietoezicht op de verschillende fases van (on)veiligheidsbeleving.

tolerance' beleid waarbij uitingen van autoriteit en macht de boventoon voeren, slaan de plank mis omdat dit bezoekers enkel uit hun onbewuste veiligheidsbeleving trekt. Wat moet worden voorkomen, is dat personen op hun hoede raken. Vormen van 'hard' toezicht en autoriteit, lijken dus enkel gerechtvaardigd in situaties waarin daadwerkelijk sprake is van een zekere dreiging.

In zulke gevallen gaat toezicht over in interventie. Dit kent twee gezichten: het wegnemen van zorg en het beëindigen van directe dreiging. De geïnterviewden geven aan dat politie-inzet, in tegenstelling tot cameratoezicht, in beide gevallen een effectief instrument is. Bij directe dreiging zullen politieagenten echter niet altijd (direct) ter plekke zijn. Het slim combineren van cameratoezicht en politietoezicht (figuur 3) zou de sleutel tot succes kunnen zijn. Politie wordt dan vanuit de cameracontrolekamer aangestuurd om op de 'juiste momenten' aanwezig te zijn terwijl zij in andere gevallen op de achtergrond kunnen blijven. Het wegnemen van zorg betreft een moeilijkere opgave. Vraag is namelijk in hoeverre camera's situaties kunnen herkennen waarin personen op hun hoede zijn. Perceptie en ervaring van andere menselijke actoren binnen het nachtleven lijkt van groot belang in het herkennen van situaties, waarbij zaken uit de hand dreigen te lopen of incidenten zich aankondigen.

In afwijkende situaties zijn uitingen van autoriteit en pogingen om veiligheid te stimuleren nuttig. Echter, in het overgrote deel van de situaties lijkt een aanpak die zich richt op het stimuleren van meer positieve emoties tijdens een avond uit effectiever: een 'zachtere' aanpak die zich in eerste instantie richt op het vergroten van plezier en het hebben van een leuke avond uit, in plaats van één waarbij al uitgegaan wordt van meer negatieve belevingen van onveiligheid.
Jelle Brands (j.brands@uu.nl) is promovendus aan de Universiteit Utrecht en werkzaam binnen het onderzoeksproject 'Surveillance in Urban Nightscapes' (www.stadsnachtwacht.nl). Dit artikel is gebaseerd op onderzoek dat wordt gefinancierd door NWO (MVi 313-99-140).

Literatuurselectie

Fussey, P. en J. Coaffee (2012) Urban spaces of surveillance. In K. Ball, K. Haggerty en D. Lyon, The Routledge Handbook of Surveillance Studies. Routledge, Abingdon, Oxford. Heidegger, M. (1962) Being and Time. Harper \& Row, New York. Helms, G., R. Atkinson en G. MacLeod (2007) Editorial. Securing the city: urban renaissance, policing and social regulation, European Urban and Regional Studies, 14(4), pp. 267-276

Roberts, M. en A. Eldridge (2009) Planning the Night-time City. Routledge, London.

Meer lezen? Eind 2013 neemt AGORA het stedelijke uitgaansleven onder de loep! Vanuit verschillende invalshoeken wordt antwoord gegeven op de vraag op hoe en door wie 'de nacht' wordt geconsumeerd, gestimuleerd en gereguleerd. Dit betekent aandacht voor de opkomst van de nachteconomie, veilig uitgaan, alcohol- en drugsgebruik en (etnische) diversiteit in clubs en uitgaanslocaties. 